\title{
Study of Lactate, Vitamin D and Nucleated Red Blood Cells for Early Prediction of Hypoxic- Ischemic Encephalopathy: A Cross-Sectional Case- Control Study
}

Ahmed Saad ( $\square$ drahmedhosni20@gmail.com )

Menoufia University Faculty of Medicine

ahmed Thabet

Menoufia University Faculty of Medicine

Mohamed Soliman

Menoufia University Faculty of Medicine

Alyaa Abdel-Aziz

Menoufia University Faculty of Medicine

\section{Research Article}

Keywords: Hypoxic Ischemic Encephalopathy, Lactate, vitamin D, Nucleated Red Blood Cells, Perinatal Asphyxia, Neonates

Posted Date: March 5th, 2021

DOl: https://doi.org/10.21203/rs.3.rs-267859/v1

License: (c) (1) This work is licensed under a Creative Commons Attribution 4.0 International License.

Read Full License 


\section{Abstract}

Objective and background

Perinatal asphyxia is a serious medical condition in which there is a lack of oxygen or blood flow during, or even after the labor process. So this study aimed to study serum blood levels of Lactate, vitamin $D$ and count of Nucleated Red Blood Cells (NRBCs) per 100 White Blood Cells (WBCs) as early biological predictors of Hypoxic-Ischemic Encephalopathy (HIE) after birth Asphyxia.

Methods

A cross-sectional case-control study was conducted on 20 neonates with HIE comprising the cases (APGAR $\leq 5)$ and another 20 neonates representing the control group with their age, sex, and weight matched, admitted to NICU from March 2020 to the end of September 2020. Venous blood samples for lactate, vitamin D and nucleated RBCs were drawn after birth and sent for analysis. Sarnat score was used to assess the severity of HIE.

Results

Venous blood levels of lactate and nucleated red blood cells per 100 white blood cells (NRBC/100 WBC) counts were significantly higher in HIE neonates than in the control group with a highly significant difference (P-value $<0.001)$. While serum Vitamin $D$ was significantly lower in the HIE group than in the control (P-value $<0.001)$.

Conclusion

Serum lactate level, vitamin D level and NRBCs/100 WBCs might be used as biomarkers in the early prediction of HIE.

\section{Introduction}

Perinatal asphyxia, also known as neonatal asphyxia or birth asphyxia, is a serious medical condition defined as a lack of blood flow or gas exchange from or to the fetus before, during, or even after the labor process [1]. Birth asphyxia can cause neurologic sequelae as a result of a low supply of blood flow or oxygen that leads to partial hypoxia or complete anoxia which may result in multi-organ failure including liver, heart, muscle, and brain; moreover, lactic acidosis and anaerobic glycolysis can occur [2]. The sequelae of birth asphyxia may end with death or other serious complications such as epilepsy, cerebral palsy, and delay in development. Moreover, the incidence of this sequelae is supposed to be higher in neonates whose mothers are diabetic or toxemic [3].

Neonatal encephalopathy that results from the decrease in cerebral perfusion, as well as systemic hypoxemia, is termed as Hypoxic-Ischemic Encephalopathy (HIE) [4]. As the therapeutic window of HIE in 
neonates can occur within only 6 hours after birth, there is an urgent need for early prediction in the course of such disease [4].

Recently, perinatal asphyxia is diagnosed by performing several measures including: Apgar score, HIE fetal signs, nucleated red blood cells (NRBCs), and biochemical markers as lactate, Lactate Dehydrogenase (LDH), and vitamin D [5]. Although there is no effective indicator that can predict birth asphyxia, it has been suggested that the increase in NRBCs count in neonate venous blood can be an early sign of birth asphyxia. Nucleated Red Blood Cells count per 100 White Blood Cells (NRBCs/100 WBCs) has been reported as a simple, quick and cheap marker for birth asphyxia [6].

As a result of hypoxia and tissue hypo-perfusion, the regular energy requirement cannot be sustained from aerobic metabolism, so that tissues go through anaerobic metabolism to get their energy requirement and hence, it reflects the increase in the production and accumulation of lactate in blood which in turn can detect tissue hypoxia at a very early stage [7].

Not many studies has issued these biological predictors in serum blood, so the aim of this study is to investigate the serum blood levels of Lactate, vitamin D and count of Nucleated Red Blood Cells per 100 White Blood Cells (RBCs/100 WBCs) as predictors of HIE after neonatal asphyxia.

\section{Patients And Methods}

This was a cross-sectional case-control study conducted on 40 neonates admitted to NICU of a tertiary hospital during the period from March 2020 to the end of September 2020. Twenty full-term neonates served as the case group was compared to another 20 full-term neonates as a control group with no risk factors of HIE. The age and sex were matched between both groups. This study was approved by the institutional Ethical committee under registration code of 91153574. Informed verbal consent was obtained from mothers after discussing the measures of the study and its importance.

\subsection{Inclusion Criteria:}

Our inclusion criteria were full-term neonates admitted to the NICU during their first 6 hours of life and met the diagnostic criteria specified by (AAP) [8] which are: base deficit $>10$, APGAR scores $\leq$ five at 10 minutes with a continued need for resuscitation, Metabolic acidosis with $\mathrm{pH}<7.0$, and Presence of primary or secondary apnea. On the other hand, we excluded every neonate aged older than 1 day, or born with any errors such as: errors of metabolism, genetic disorders, congenital neurologic disorders, or medication effect.

\subsection{Study Process:}

Both groups included in our study were subjected to full detailed history as follows: prenatal history, natal history, postnatal history, and family history. Besides a clinical examination includes baseline data such as gender, gestational age, vital signs, birth weight, and head circumference as well as any relative 
clinical findings. We used the Sarnat score [9] to classify the degree of encephalopathy whether it is mild, moderate, or severe in which it indicates the mild, moderate, and severe encephalopathy status.

In patient group, we used a radiological examination to further assess the grades of encephalopathy by cranial ultrasound as a routine inpatient investigation with brain insult.

\subsection{Investigation:}

Regarding the investigations, $2 \mathrm{ml}$ of fresh venous blood samples were withdrawn from neonates in the $1^{\text {st }} 24$ hours after delivery under complete aseptic condition. Routine lab investigations such as complete blood count (CBC), liver function, kidney function, random blood glucose, arterial blood gases, C-reactive protein were also measured at admission. Ten microns of blood were administrated in a vacutainer tube containing EDTA so we can assess the blood film of nucleated red blood cells by staining thin blood smear using Leishman stain; furthermore, it was examined by high power field microscope (100x). We used Mindray auto analyzer to assess serum lactate level in ten microns of venous blood by adding enzymatic colorimetric method (LOX/PAP) with lactate oxidase and 4-aminoantipyrine and (RIST) reagent $40 \mathrm{mg} / \mathrm{dl}$. Lastly, we used Stat Fax 4500 to measure serum vitamin D level in 100 microns of a blood sample by centrifugation of the sample at $4000 \mathrm{rpm}$ for about 10 minutes.

\subsection{Statistical Analysis}

The data were coded, collected on an Excel sheet, and processed using SPSS 25. Descriptive statistics were represented by percent (\%), and number $(\mathrm{N})$. Mean, standard deviation (SD), range, minimum and maximum, and median were all used to describe quantitative data.

Chi-square test $\left(\chi^{2}\right)$ : was used to study the relation between two qualitative variables. One-way analysis of variance (ANOVA) or ( $F$ test) was used to find any significant difference between different groups with a normally distributed quantitative variable. A post hoc test with the Least Significant Difference (LSD) was performed. For pairwise comparisons, Mann Whitney $U$ test and Kruskual-Wallis (which are a nonparametric test of significance) was used to compare between two groups having quantitative variables but not normally distributed.

P-value was considered to be highly significant if $P<0.001$, significant if $P \leq 0.05$, and not-significant if $P$ $>0.05$. Receiver operating characteristic (ROC) curves were established to assess the sensitivity and specificity by using SPSS. We used the combination of highest sensitivity and specificity which were determined at the apex of the ROC curve as the chosen clinical values. An ideal curve of a reasonable test should contain a larger area under the ROC graph. The P-value $<0.05$ was considered the cut-off value for significance.

\section{Results}


Fifty-seven babies were admitted to the NICU in of which 17 patients were excluded, as they do not match our inclusion criteria (figure 1). So 40 neonates were included in our study and allocated into two groups; the first group (HIE group) consists of 20 full-term neonates who were diagnosed as HIE cases according

to the diagnostic criteria set by AAP, and the second group (Control group) consists of 20 age, weight and sex-matched full-term neonates with no risk factors of HIE.

\subsection{Participants Characteristics:}

There was no statistically significant difference between both groups as regard gender, body weight, and gestational age (P-value > 0.05). But there was a high significance in Apgar score which was lower in HIE neonates compared to the controls ( $P$-value $<0.0001)$ (Table 1$)$.

Sarnat score revealed about $25 \%$ of the patients were assigned as mild HIE, $35 \%$ as moderate HIE, and $40 \%$ as severe HIE.

\subsection{Outcomes:}

Mann-Whitney test and student's t-test revealed great significance between both groups regards serum lactate level [mg/dl] and NRBC/100 WBC which were much higher in the HIE group than the control group (P-value <0.001). The results also showed that vitamin D level was lower in the HIE group than the control group (P-value <0.001) (Table 3).

We also compared the same outcomes between different HIE grades. But we didn't find any significance between HIE grades regards vitamin D level and NRBC/100 WBCs count (P-value $=0.08,0.089$ respectively). With the significant difference in terms of mortality and serum Lactate level, severe HIE grade had the highest percentage of mortality (7 out of 8). And moderate HIE grade had the highest level of serum lactate level.

Post hoc analysis was used to measure the effect estimate between grades and each other. The post hoc between mild and moderate and between mild and severe were significant. The post hoc between moderate and severe was not significant (Table 4).

\subsection{Diagnostic accuracy:}

The best cutoff value of NRBC/100 WBCs to detect hypoxia was $>2.5 / 100$ WBCs with a sensitivity of $100 \%$, specificity $73.3 \%$, PPV $77 \%$, NPV $88 \%$ and diagnostic accuracy $81 \%$. The best cutoff of serum lactate level to detect hypoxia was $>51.56 \mathrm{mg} / \mathrm{dl}$ (P-value $<0.001)$. This yielded a sensitivity of $100 \%$, specificity $80 \%$, PPV $83 \%$ and NPV $100 \%$ with a diagnostic accuracy of $90 \%$. As regard vitamin D serum level, the best cutoff to detect hypoxia was $<32 \mathrm{pg} / \mathrm{ml}$ which yielded a sensitivity of $100 \%$, Specificity 95\%, NPV 100\%, PPV 95\%, and good manner accuracy with 97\% (Table 5).

\subsection{Statistical correlation:}


We assessed the correlation between serum lactate and other parameters (Table 7) and it revealed a negative significant correlation between Serum Lactate and (weight, Apgar score, $\mathrm{PH}, \mathrm{HCO}$, and serum Vit $D)(P \llbracket 0.05)$ (Table 7). There was a positive significant correlation between Serum Lactate and PCO2, urea, Sarnat score for HIE grading, duration of incubation, and NRBC/100 WBCs count (P $₫ 0.05)$. Besides, there was no significant correlation between serum Lactate and gestational age along with creatinine ( $P$ value $>0.05$ ).

Regarding the correlation between NRBC/100 WBC and other parameters. A negative significant correlation between NRBC/100WBC and weight, Apgar score, $\mathrm{PH}, \mathrm{HCO}$, and serum Vit $\mathrm{D}$ was detected ( $\mathrm{P}$ $\bowtie 0.05)$ (Table 7). Moreover, a positive significant correlation between NRBC/100WBC and PCO2, urea, Sarnat score for HIE grading, and length of incubation was revealed (P $₫ 0.05)$. However, there was no significant correlation between NRBCs/100WBC and gestational age along with creatinine (P-value $>0.05)$ (Table 7).

There was a positive significant correlation between serum Vit $D$ and gestational age, weight, Apgar score, $\mathrm{PH}$ with $\mathrm{HCO} 3(\mathrm{P} \otimes 0.05)$. There was a negative significant correlation between serum Vit $\mathrm{D}$ and $\mathrm{PCO} 2$, urea, Sarnat score for HIE grading and duration of incubation (Pख0.05). There was no significance in the correlation between serum Vit $D$ and creatinine ( $P$-value $>0.05$ ) (Table 7).

\section{Discussion}

The incidence of perineal Hypoxic-ischemic encephalopathy (HIE) in developing countries is several higher compared to other countries, ranging from 4.6 per 1000 full-term neonates with case fatality rates of more than $40 \%$ [10]. HIE can induce permanent perineal morbidity, neurological handicap, and mortality. The early prediction of such disease is very important as the outcomes of HIE are permanent and devastating. In addition to its low therapeutic window and major side effects that can result from interventions of neuro protective equipment [11].

In this study, the median Apgar score at $5 \mathrm{~min}$ in the HIE group was 2.5 which was significantly lower compared to the control group which was 10; this finding was aligned with other studies that revealed low Apgar score associated with neonates born with perinatal asphyxia who later developed HIE $[12,13]$.

As regards NRBC, previous studies had issued NRBC as a hematopoietic marker in newborn babies with a strong relation to the intrauterine hypoxia, as the increase in NRBC count in infant's blood circulation results from the boosting activity of erythropoietin. Moreover, it's not only considered a biomarker for HIE but also predicts the risk of complications that occurred during $\operatorname{HIE}[14,15]$. In this study, we found the levels of NRBC/100 WBC in venous blood were higher in the HIE group than the control group achieving a mean of 6.60 in the HIE group and zero in the control group which was a huge difference compared to other studies who mentioned the NRBCs count level [11-18]. This difference between this study and other studies was because they measured NRBCs count in umbilical cord blood, but we measured this count in venous blood. 
Also, the NRBC/ 100 WBC set to diagnose HIE achieved sensitivity of $100 \%$, specificity $73.3 \%$, NPV $88 \%$, PPV $77 \%$, accuracy $81 \%$ at best cutoff $>2.5$. Moreover, the area under the curve of ROC was 0.917 with a $\mathrm{p}$-value $<0.001$. This comes in agreement with some studies, which stated that the levels of NRBC per 100 WBC were higher in HIE than in control one when they detect the variable in cord blood $[13,15]$. Even though the exact mechanism is still unclear, it may be accompanied by the increase in erythropoietin level in blood which in turn induces the increase in NRBCs count over the increase in mitotic divisions of normoblasts $[16,17]$.

Regards serum lactate level, the mean serum lactate level in the HIE group was $71.03 \mathrm{mg} / \mathrm{dl}$ while it was $15.5 \mathrm{mg} / \mathrm{dl}$ in the control group revealing a highly significant difference between both groups as the $\mathrm{p}$ value was $<0.001$. But there was no association between grades of HIE and level of serum lactate level as moderate is the highest value of lactate level while mild is the lowest one [18]. This comes in agreement with another study that showed that the serum lactate level was higher in HIE neonates than the control; however, it stated that the more severe form of neonatal hypoxia the more serum lactate [18]. The association between the severity of HIE grades and neurological development issues in neonates was stated by some studies, hence early prediction of HIE signs with early proper treatment is a must $[19,20]$.

In this study, blood levels of lactate set to diagnose HIE were $>71.03 \mathrm{mg} / \mathrm{dl}$ that yielded a sensitivity of $100 \%$, specificity $80 \%$, NPV $100 \%$, and PPV $83 \%$. Also, the overall accuracy was good with $90 \%$ with area under ROC curve of $0.913, p<0.001$ with cutoff $>51.56$. This comes in alignment with some studies that stated that the blood level of lactate with reasonable sensitivity and specificity scores could be used as a predictor of intrapartum hypoxia [18-21].

As regard serum vitamin D level, the HIE group mean was $7.11 \mathrm{pg} / \mathrm{ml}$ while it was $56.15 \mathrm{pg} / \mathrm{ml}$ in the control group with a highly significant lower score in the HIE group than the control group ( $p$-value $<0.001)$. This finding was primarily because of maternal deficiency and poor supplements. Also, this comes in agreement with some studies which showed a strong association between HIE disease and vitamin D deficiency [20-22], and the serum level of vitamin D in neonates often continues to decline for about 72h [23]. Although there is an association between HIE and Vit D deficiency, the exact interactions and mechanism still unclear.

All past studies [13-23] that illustrated the NRBCs count per 100 WBC, Vitamin D level, and serum lactate level were measuring these variables by umbilical cord blood; however we measured the same variables in venous blood levels and figured out matched results compared to umbilical cord blood results.

This study focused on venous blood as there are few studies that mentioned NRBC/100 WBC, serum lactate, and Vit $D$ in venous blood, rather than many studies that focused on cord blood samples. The results of this study adds to knowledge of being a mid-high reliable source assessing these parameters in venous blood.

The first limitation of this study was the small sample size enrolled, as there were no chance to collect data from other hospital rather than the two hospitals included in this study; thus giving the results low 
impact in the medical knowledge. Besides, the study was a cross sectional case control which may maximize the standard error of the study, as well as the limitations shared of cross-sectional studies. We recommend further clinical trials with higher sample size to precise these results along with few limitations.

\section{Conclusion}

This study showed that lactate blood level, serum vitamin D level, and NRBC/100 WBCs could help in the early prediction of HIE disease as they are easy to apply, cheap in cost, and non-invasive measures.

\section{Declarations}

Funding: Not applicable.

Conflict of interests: No conflict between authors

Availability of data and material: NA

\section{Code availability: NA}

\section{Author's contribution:}

1] Ahmed Hosni: Writing and analysis; 2] Ahmed Thabet: Data reporting and manuscript formatting; 3] Mohamed Soliman: Data analysis and initial writing; 4] Alyaa Abdel-Aziz: Approval of submission with revision.

Ethical Approval: This study was approved by the institutional Ethical committee under registration code of 91153574

Consent to participate: Informed verbal consent was obtained from mothers after discussing the measures of the study and its importance

Consent for publication: All authors confirm the originality of this work and give the full permission to the [European journal of Pediatrics] to publish this study.

\section{References}

[1] Sugiura-Ogasawara M, Ebara T, Yamada Y, Shoji N, Matsuki T, Kano H, Kurihara T, Omori T, Tomizawa M, Miyata M, Kamijima M, Saitoh S., Japan Environment, Children's Study (JECS) Group. Adverse pregnancy and perinatal outcome in patients with recurrent pregnancy loss: Multiple imputation analyses with propensity score adjustment applied to a large-scale birth cohort of the Japan Environment and Children's Study. Am J Reprod Immunol. 2019 Jan; 81(1):e13072. 
[2] Hakobyan M, Dijkman KP, Laroche S, Naulaers G, Rijken M, Steiner K, van Straaten HLM, Swarte RMC, Ter Horst HJ, Zecic A, Zonnenberg IA, Groenendaal F. Outcome of Infants with Therapeutic Hypothermia after Perinatal Asphyxia and Early-Onset Sepsis. Neonatology. 2019;115(2):127-133.

[3] Pokorná P., et al. "Severity of asphyxia is a covariate of phenobarbital clearance in newborns undergoing hypothermia". Journal of Maternal-Fetal and Neonatal Medicine 5 (2018): 1-8.

[4] Ahearne CE., et al. "Short and long term prognosis in perinatal asphyxia: An update". World Journal of Clinical Pediatrics 5.1 (2016): 67-74.

[5] Boskabadi H, Tavakol Afshari J, Maamouri G, Ghayour-Mobarhan M, Ferns G. Association between serum interleukin-6 levels and severity of perinatal asphyxia. Asian Biomedicine. 2010;4(1):79-85

[6] Martin RJ, Fanaroff AA, Walsh MC. Neonatal-perinatal medicine: diseases of the fetus and infant: Elsevier/Mosby; 2011.

[7] Einikyte R., et al. "The comparison of umbilical cord arterial blood lactate and pH values for predicting short-termneonatal outcomes". Taiwanese Journal of Obstetrics and Gynecology 56.6 (2017): 745-749.

[8] Blackmon LR., et al. "Hypothermia: a neuroprotective therapy for neonatal hypoxic-ischemic encephalopathy". Pediatrics 117.3 (2006): 942-948.

[9] Mrelashvili, A., Russ, J.B., Ferriero, D.M. et al. The Sarnat score for neonatal encephalopathy: looking back and moving forward. Pediatr Res 88, 824-825 (2020). https://doi.org/10.1038/s41390-020-01143-5

[10] Batool AH, Zulfiqar A.B. Birth Asphyxia in Developing Countries: Current Status and Public Health Implications. Curr Probl Pediatr Adolesc Health Care, June 2006.

[11] Guan B., et al. "Early diagnosis and outcome prediction of neonatal hypoxic-ischemic encephalopathy with color Doppler ultrasound". Diagnostic and Interventional Imaging 98.6 (2017):469475 .

[12] Leybovitz-Haleluya N., et al. "Low Apgar scores in term newborns and long-term gastro-intestinal morbidity: a population based cohort study with up to 18 years of follow-up". Journal of Maternal-Fetal and Neonatal Medicine 7 (2017): 1-6.

[13] Mohamed Shawky Elfarargy., et al. "Study of Lactate and Nucleated Red Blood Cells as Early Predictors of Neonatal Hypoxic Ischemic Encephalopathy". Acta Scientific Paediatrics 1.2 (2018): 03-08

[14] Blackwell SC, Hallak M, Hotra JW, Refuerzo J, Hassan SS, Sokol RJ, et al. Timing of fetal nucleated red blood cell count elevation in response to acute hypoxia. Neonatology. 2004; 85(4):217-20. 
[15] McCarthy J, Capullari T, Thompson Z, Zhu Y, Spellacy W. Umbilical cord nucleated red blood cell counts: normal values and the effect of labor. Journal of perinatology. 2006; 26(2):89- 92

[16] Iversen P. Blood flow to the haemopoietic bone marrow. Acta physiologica scandinavica. 1997; 159(4):269-76.

[17] Lichtman MA. Williams hematology: McGraw-Hill New York; 2006

[18] Chiang MC., et al. "Serum Lactate, Brain Magnetic Resonance Imaging and Outcome of Neonatal Hypoxic Ischemic Encephalopathy after Therapeutic Hypothermia". Pediatrics and Neonatology 57.1 (2016): 35-40.

[19] Perez A, Ritter S, Brotschi B, Werner H, Caflisch J, Martin E, et al. Long-term neurodevelopmental outcome with hypoxic-ischemic encephalopathy. The Journal of pediatrics. 2013; 163(2):454-9. e1.

[20] De Vries LS, Jongmans MJ. Long-term outcome after neonatal hypoxic-ischaemic encephalopathy. Archives of Disease in Childhood-Fetal and Neonatal Edition. 2010; 95(3):F220-F4

[21] Da Silva S, Hennebert N, Denis R, Wayenberg JL. Clinical value of a single postnatal lactate measurement after intrapartum asphyxia. Acta Paediatr. 2000; 89(3):320-3.

https://doi.org/10.1111/j.1651-2227.2000.tb01334.x PMid: 10772280

[22] Mutlu M, Sariaydin M, Aslan Y, Kader Ş, Dereci S, Kart C, Özer Yaman S, Kural B: Status of vitamin D, antioxidant enzymes, and antioxidant substances in neonates with neonatal hypoxic-ischemic encephalopathy. J Matern Fetal Neonatal Med 2016;29:2259-2263.

[23] Lowe D, Hollis B, Wagner C, Bass T, Kaufman D, Horgan M, Givelichian L, Sankaran K, Yager J, Katikaneni L, Wiest D, Jenkins D: Vitamin D insufficiency in neonatal hypoxicischemic encephalopathy. Pediatr Res 2017; 82:55-62.

\section{Tables}

Table 1: Demographic data and Apgar score of HIE and control infants. 


\begin{tabular}{|c|c|c|c|c|}
\hline $\mathrm{N}$ & $\begin{array}{l}\text { HIE Group } \\
\mathrm{N}=20\end{array}$ & $\begin{array}{l}\text { Control group } \\
\mathrm{N}=20\end{array}$ & $95 \% \mathrm{Cl}$ & P-value \\
\hline \multicolumn{5}{|l|}{$\operatorname{Sex} N(\%)$} \\
\hline Male & $9(45 \%)$ & $13(65 \%)$ & - & 0.20 \\
\hline Female & $11(55 \%)$ & $7(35 \%)$ & & \\
\hline \multicolumn{5}{|c|}{ Gestational age (week) } \\
\hline Mean \pm SD & $36.75 \pm 2.24$ & $37.6 \pm 0.94$ & {$[-0.249-1.949]$} & 0.13 \\
\hline \multicolumn{5}{|l|}{ Weight } \\
\hline Mean \pm SD & $3.22 \pm 0.32$ & $3.18 \pm 0.23$ & {$[-0.138-0.218]$} & 0.65 \\
\hline \multicolumn{5}{|c|}{ Apgar score at $5 \mathrm{~min}$} \\
\hline Mean \pm SD & $4.50 \pm 2.16$ & $7.8 \pm 2.02$ & {$[1.961-4.639]$} & $\varangle 0.001$ \\
\hline
\end{tabular}

$\otimes 2=$ chi-square test $U=$ Mann-Whitney test $t=$ student's $t$-test NS=Non-Significant

Categorical data were represented as number (percentage), and Descriptive data were represented by mean \pm standard deviation (SD).

Table 2: laboratory finding of HIE group and control group

\begin{tabular}{|c|c|c|c|c|}
\hline & $\begin{array}{l}\text { HIE Group } \\
\mathrm{N}=20\end{array}$ & $\begin{array}{l}\text { Control group } \\
\mathrm{N}=20\end{array}$ & $95 \% \mathrm{Cl}$ & $P$ value \\
\hline \multicolumn{5}{|l|}{$\mathrm{PH}$} \\
\hline Mean \pm SD & $7.11 \pm 0.165$ & $7.39 \pm 0.03$ & {$[0.2-0.355]$} & $\varangle 0.001$ \\
\hline \multicolumn{5}{|l|}{ PCO2 } \\
\hline Mean \pm SD & $42.60 \pm 11.5$ & $29.20 \pm 7.46$ & [7.195 - 19.6] & $\varangle 0.001$ \\
\hline \multicolumn{5}{|l|}{$\mathrm{HCO} 3$} \\
\hline Mean \pm SD & $12.2 \pm 3.88$ & $15.32 \pm 2.66$ & [0.99-5.25] & 0.005 \\
\hline \multicolumn{5}{|l|}{ ALT } \\
\hline Mean \pm SD & $22.7 \pm 7.07$ & $15.95 \pm 2.32$ & [3.38 - 10.11] & $\llbracket 0.001$ \\
\hline \multicolumn{5}{|l|}{ AST } \\
\hline Mean \pm SD & $30.80 \pm 6.97$ & $23.45 \pm 2.37$ & {$[4.02-10.68]$} & $\otimes 0.001$ \\
\hline
\end{tabular}

$\mathrm{t}=$ student's $\mathrm{t}$-test $\mathrm{S}=$ Significant $\quad \mathrm{HS}=$ High significant 
Descriptive data were represented by mean $\pm S D$

Table 3: Comparison between HIE group and control group as regarding serum Lactate, Vitamin D and Nucleated Red Blood Cells

\begin{tabular}{|llll|}
\hline & $\begin{array}{l}\text { HIE Group } \\
\mathrm{N}=\mathbf{2 0}\end{array}$ & $\begin{array}{l}\text { Control group } \\
\mathrm{N}=\mathbf{2 0}\end{array}$ & P value \\
\hline $\begin{array}{l}\text { Serum Lactate } \mathrm{mg} / \mathrm{dl} \\
\text { Mean } \pm \text { SD }\end{array}$ & $71.03 \pm 19.1$ & $15.5 \pm 3.17$ & $\varangle 0.001$ \\
\hline $\begin{array}{l}\text { Serum vit D pg/ml } \\
\text { Mean } \pm \text { SD }\end{array}$ & $7.11 \pm 4.06$ & $56.15 \pm 14.4$ & $\varangle 0.001$ \\
\hline $\begin{array}{l}\text { NRBC/100WBC } \\
\text { Mean } \pm \text { SD }\end{array}$ & $6.60 \pm 4.59$ & 0 & \\
\hline
\end{tabular}

$\mathrm{U}=$ Mann-Whitney test $\mathrm{t}=$ student's $\mathrm{t}$-test $\quad \mathrm{HS}=$ High significant

Descriptive data were represented by mean $\pm S D$

Table 4: Comparison between the three grades of hypoxia as regarding nucleated red blood cells, serum lactate level, Vitamin D and outcome.

\begin{tabular}{|c|c|c|c|c|}
\hline & \multicolumn{3}{|l|}{ HIE grads } & \multirow[t]{3}{*}{$P$ value } \\
\hline & Mild & Moderate & Severe & \\
\hline & No $=5$ & $\mathrm{No}=7$ & No $=8$ & \\
\hline \multicolumn{5}{|c|}{ Outcome N (\%) } \\
\hline Discharge & $4(80 \%)$ & $5(71.4 \%)$ & $1(12.5 \%)$ & \multirow[t]{2}{*}{0.02} \\
\hline Died & $1(20 \%)$ & $2(28.6 \%)$ & $7(87.5 \%)$ & \\
\hline \multicolumn{5}{|c|}{ Serum Lactate $\mathrm{mg} / \mathrm{dl}$} \\
\hline Mean \pm SD & $49.26 \pm 20.85$ & $79.3 \pm 11.2$ & $77.3 \pm 13.3$ & 0.03 \\
\hline Post hoc & \multicolumn{4}{|c|}{$P 1=0.008 \quad P 2=0.01 \quad P 3=0.78$} \\
\hline \multicolumn{5}{|c|}{ Serum vit D pg/ml } \\
\hline Mean \pm SD & $10.6 \pm 3.64$ & $5.92 \pm 3.35$ & $5.97 \pm 3.99$ & 0.08 \\
\hline \multicolumn{5}{|c|}{ Nucleated Red Blood Cells/100WBC } \\
\hline Mean \pm SD & $3.30 \pm 2.70$ & $7.85 \pm 3.97$ & $7.50 \pm 5.45$ & 0.089 \\
\hline
\end{tabular}


FXT=Fischer's exact test $\quad K=$ Kruskual waills test

$\mathrm{P} 1=$ Grade 1 vs Grade $2 \quad \mathrm{P} 2=$ Grade 1 vs Grade 3

P3= Grade 2 vs Grade 3

Categorical data were represented as number (percentage), and Descriptive data were represented by mean \pm standard deviation (SD).

Table 5: Validity of serum Lactate, vitamin D and nucleated red Blood cells as early predictors of HIE Mortality

\begin{tabular}{|lllllllll|}
\hline & AUC & $\begin{array}{l}\text { p- } \\
\text { value }\end{array}$ & Cutoff & Sn & Sp & NPP & PPV & Accuracy \\
\hline serum Lactate & $\mathbf{0 . 9 1 3}$ & $\varangle 0.001$ & $\varangle 51.56$ & $100 \%$ & $80 \%$ & $100 \%$ & $83 \%$ & $90 \%$ \\
\hline Vitamin D & 1.00 & $\varangle 0.001$ & $\varangle 32$ & $100 \%$ & $95 \%$ & $100 \%$ & $95 \%$ & $97 \%$ \\
\hline $\begin{array}{l}\text { Nucleated Red Blood } \\
\text { Cells }\end{array}$ & $\mathbf{0 . 9 1 7}$ & $\nabla 0.001$ & $\varangle 2.5$ & $100 \%$ & $73.3 \%$ & $88 \%$ & $77 \%$ & $81 \%$ \\
\hline
\end{tabular}

AUC: Area under curve, Sn: sensitivity, Sp: specificity, NPP: Negative predictive value, PPV: positive predictive value.

Table 6: clinical findings in HIE group and Control group: 


\begin{tabular}{|c|c|c|c|}
\hline & $\begin{array}{l}\text { HIE Group } \\
\mathrm{N}=20\end{array}$ & $\begin{array}{l}\text { Control group } \\
\mathrm{N}=20\end{array}$ & $P$ value \\
\hline \multicolumn{4}{|l|}{ Sepsis } \\
\hline Yes & 13 (65\%) & $16(80 \%)$ & 0.288 \\
\hline No & 7 (35\%) & $4(20 \%)$ & \\
\hline \multicolumn{4}{|l|}{ Mortality } \\
\hline Survived & $10(50 \%)$ & 20 (100\%) & $\llbracket 0.001$ \\
\hline Died & $10(50 \%)$ & $0(0 \%)$ & \\
\hline \multicolumn{4}{|c|}{ Duration of PICU stay (days) } \\
\hline Mean \pm SD & $8.25 \pm 5.60$ & $4.75 \pm 1.91$ & 0.014 \\
\hline \multicolumn{4}{|l|}{ Urea } \\
\hline Mean \pm SD & $34.65 \pm 19.4$ & $17.45 \pm 1.63$ & $\otimes 0.001$ \\
\hline \multicolumn{4}{|l|}{ Creatinine } \\
\hline Mean \pm SD & $0.73 \pm 0.27$ & $0.65 \pm 0.15$ & 0.299 \\
\hline
\end{tabular}

$\mathrm{U}=$ Mann-Whitney test $\mathrm{t}=$ student's $\mathrm{t}$-test $\quad \mathrm{FXT}=$ Fisher's exact test $\otimes 2=$ chi-square test $\quad H S=$ High significant

Categorical data were represented as number (percentage), and Descriptive data were represented by mean \pm standard deviation (SD).

Table 7: correlation between Serum Lactate, NRBC, Vit D and other parameters 


\begin{tabular}{|c|c|c|c|c|c|c|}
\hline \multirow[t]{2}{*}{ Parameters } & \multicolumn{2}{|c|}{ Serum Lactate } & \multicolumn{2}{|c|}{ NRBC/100 WBC } & \multicolumn{2}{|c|}{ Serum Vit D } \\
\hline & $r$ & P-value & rho & P-value & rho & P-value \\
\hline Gestational age & -0.209 & 0.196 & -0.171 & 0.290 & 0.314 & 0.049 \\
\hline Weight & -0.445 & 0.004 & -0.425 & 0.006 & 0.506 & 0.001 \\
\hline Apgar score & -0.944 & $₫ 0.001$ & -0.955 & $\llbracket 0.001$ & 0.808 & $\varangle 0.001$ \\
\hline $\mathrm{PH}$ & -0.832 & $₫ 0.001$ & -0.878 & $\llbracket 0.001$ & 0.754 & $\varangle 0.001$ \\
\hline Pco2 & 0.690 & 0.001 & 0.634 & 0.001 & -0.407 & 0.009 \\
\hline $\mathrm{Hco3}$ & -0.588 & $\varangle 0.001$ & -0.529 & $\llbracket 0.001$ & 0.444 & 0.004 \\
\hline Urea & 0.573 & $\triangle 0.001$ & 0.627 & $\llbracket 0.001$ & -0.564 & $₫ 0.001$ \\
\hline Creatinine & 0.231 & 0.152 & 0.173 & 0.258 & -0.201 & 0.214 \\
\hline Sarnat Score for HIE grading & 0.906 & $\otimes 0.001$ & 0.912 & $\llbracket 0.001$ & -0.865 & $\triangle 0.001$ \\
\hline Duration of PICU stay & 0.386 & 0.014 & 0.325 & 0.014 & -0.370 & 0.019 \\
\hline Serum vit $D$ & -0.884 & $凶 0.001$ & -0.814 & $\llbracket 0.001$ & - & - \\
\hline NRBC/100 WBC & 0.888 & $\$ 0.001$ & - & - & - & -- \\
\hline
\end{tabular}

$r=$ Pearson correlation, $r$ ho $=$ Spearman correlation

\section{Figures}




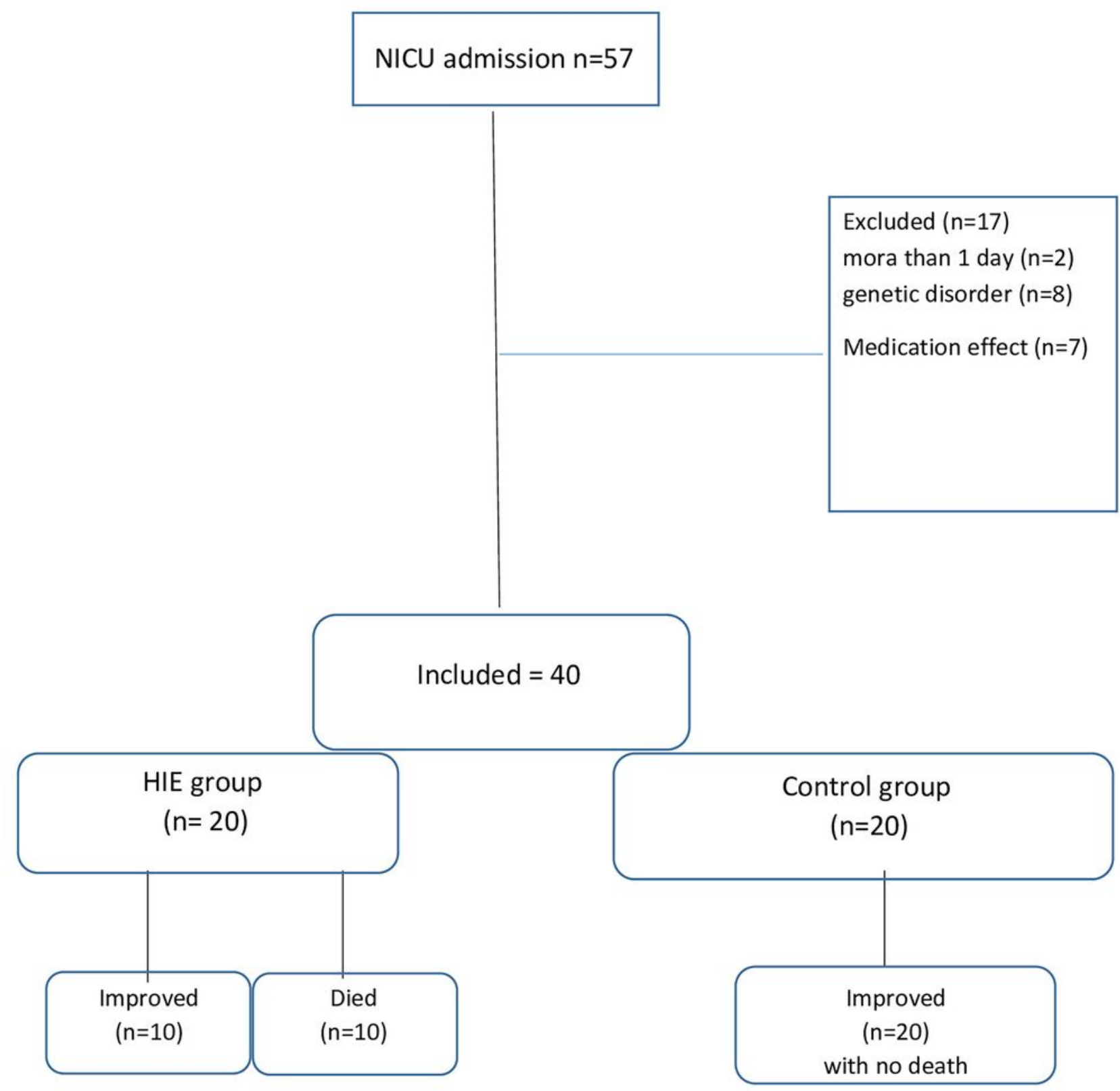

Figure 1

Temporal Profile of subject admitted to Neonatal intensive care unit 